\title{
REMOVAL OF As (V) BY USING BOTTOM ASH AS ADSORBENT
}

\section{Meral Yildirim, ${ }^{1}$ Nevin Karamahmut Mermer, ${ }^{2}$ Funda Demir, ${ }^{3}$ Emek Moroydor Derun ${ }^{4}$}

\begin{abstract}
Industrial development brings waste problem which is a challenge for both human health and ecological cycle. Arsenic is a toxic and carcinogenic heavy metal that should be removed from drinking or waste water. In this study, an industrial waste of bottom ash was used as an adsorbent to remove As (V). To find an appropriate adsorption conditions, the adsorption temperatures and contact time were varied between $30{ }^{\circ} \mathrm{C}-50{ }^{\circ} \mathrm{C}$ and $5-180 \mathrm{~min}$, respectively. The experimental results were fitted to the Langmuir and Freundlich isotherms. The highest values of $n$ and $\mathrm{K}_{\mathrm{F}}$ for Freundlich isotherm were obtained for $30{ }^{\circ} \mathrm{C}$ and calculated as 0.432 and 0.006 , respectively. According to kinetic studies, the kinetics of these experiments could be explained by pseudo-second order kinetic model, and the pseudo-second order rate constant was calculated as $0.034 \mathrm{~g} / \mathrm{mg} . \mathrm{min}, 0.033 \mathrm{~g} / \mathrm{mg}$.min and $0.030 \mathrm{~g} / \mathrm{mg} \cdot \mathrm{min}$ for $30^{\circ} \mathrm{C}, 40{ }^{\circ} \mathrm{C}$ and $50{ }^{\circ} \mathrm{C}$, respectively. According to experimental results, bottom ash can be used for removal of As (V) from water sources.
\end{abstract}

UDC Classification: 66.03; DOI: http://dx.doi.org/10.12955/cbup.v5.1106

Keywords: Adsorption, arsenic, bottom ash, ICP-OES

\section{Introduction}

Heavy metal pollution is a remarkable threat for both human health and environment which is resulted by increasing in industrial activities and urbanization. The trace elements like lead $(\mathrm{Pb})$, cadmium $(\mathrm{Cd})$, zinc $(\mathrm{Zn})$, mercury $(\mathrm{Hg})$, arsenic $(\mathrm{As})$, silver $(\mathrm{Ag})$, chromium $(\mathrm{Cr})$, copper $(\mathrm{Cu})$, and iron $(\mathrm{Fe})$ can accumulate unnoticed to toxic levels and cause many diseases and even death (Duruibe et al., 2007; Yang et al., 2016).

Arsenic is a hazardous, toxic and carcinogenic metalloid which can get into drinking water, underground water, etc. and causes environmental problems by soil erosion and leaching. Additionally, industrial applications such as mining, fuel combustion, using arsenic as pesticide bring about arsenic pollution. Because of its toxicity, the World Health Organization (WHO) limit the occurrence of arsenic in drinking water as $10 \mathrm{mg} / \mathrm{L}$ (Mohan et al., 2007; El-Moselhy et al., 2017; Banerji \& Chaudhari, 2016). Thus, an effective removal of arsenic from aqueous solutions, as well as other heavy metals, is an important issue to investigate.

There are many approaches to remove arsenic from drinking and waste water including electrocoagulation (Banerji \& Chaudhari, 2016), ion exchange, membrane separation, adsorption and precipitation (Zhou et al., 2016; Mohan \& Pittman, 2007). Being a low cost, easy to operate and efficient method, adsorption process is widely studied for the removal of arsenic from aqueous solutions by use of adsorbent materials such as activated carbon and zeolites.

In recent years, studies have been focused on alternative adsorbents which are derived from industrial wastes. Industrial wastes like rice husk, peanut shells, fly ash, coconut husk, waste coffee and tea has been recycled to low-cost biosorbents (Cheraghi et al., 2015; Yang et al., 2016; Uddin et al., 2009).

Coal-fired thermal power plants have led to an increase in the occurrence of many solid wastes such as fly ash and bottom ash (Fonteboa et al., 2017; Noh \& Son, 2017). When bottom ash is obtained from bottom chamber and contains mineral impurities, fly ash is collected in the electrostatic precipitators or the filters. Because of the high energy demand, the production of these industrial wastes is increasing. On the other hand, the chemical and physical properties of these materials provide their use in many different sectors. Fly ash and bottom ash are widely evaluated in the cement, ceramic, paint, plastic, agriculture, environment and construction applications (Eliche-Quesada et al., 2017). However, there are a few studies that used bottom ash as an adsorbent for removing heavy metals from water. In the study conducted by Lin \& Yang (2002), the adsorption of $\mathrm{Cu}$ (II) was carried out by coal bottom ash and results showed that coal bottom ash could be an excellent adsorbent for the pollutant in the waste water (Lin \& Yang, 2002). Orakwue (2016) compared the adsorption capacities of fly ash, bottom ash and bentonite for adsorption of Iron(II) from acid mine drainage contaminated ground

\footnotetext{
${ }^{1}$ Yildiz Technical University, Istanbul, Turkey, meraly@ yildiz.edu.tr

2 Yildiz Technical University, Istanbul, Turkey, nevinkaramahmut@ hotmail.com

${ }^{3}$ Yildiz Technical University, Istanbul, Turkey, demirfunda1 @ hotmail.com

${ }^{4}$ Yildiz Technical University, Istanbul, Turkey, moroydor@yildiz.edu.tr
} 
water and found out that adsorption capacity value of bottom ash was higher than other adsorbents (Orakwue et al., 2016).

The main objective of this study was to investigate the removal of As (V) from the aqueous medium through batch adsorption by bottom ash as a low-cost adsorbent. The adsorption capacity of bottom ash was determined by varying adsorption parameters of contact time and adsorption temperature.

\section{Experimental Studies}

Materials

Bottom ash was supplied from Çelikler Seyitömer Electricity Generation Plant (Kutahya, Turkey). Before use in experimental studies, the supplied bottom ash was dried in an incubator (Ecocell 111, Germany) at $105^{\circ} \mathrm{C}$ for 12 hours to eliminate its moisture. After drying, the adsorbent was grounded and sieved by vibratory sieve-shaker (Fritsch, Germany) to access a particle size of below $90 \mu \mathrm{m}$. The elemental composition of prepared adsorbent was determined by X-ray fluorescence (XRF) (Rigaku, NEX CG, Canada) in the range of Na-U elements. The BET surface area of bottom ash was measured on a Micromeritics ASAP 2020 instrument using $\mathrm{N}_{2}$ adsorption after degassing adsorbents at $400{ }^{\circ} \mathrm{C}$ for 12 hours. The properties of bottom ash are given in Table 1.

\begin{tabular}{|c|c|c|c|}
\hline & \multicolumn{2}{|c|}{ Elemental composition } & \multirow[t]{2}{*}{ BET Surface area $\left(\mathrm{m}^{2} / \mathrm{g}\right)$} \\
\hline & Compound & Percentage (\%) & \\
\hline & $\mathrm{SiO}_{2}$ & 47.5 & \multirow{9}{*}{55.09} \\
\hline & $\mathrm{Al}_{2} \mathrm{O}_{3}$ & 15.4 & \\
\hline & $\mathrm{Fe}_{2} \mathrm{O}_{3}$ & 11.6 & \\
\hline & $\mathrm{MgO}$ & 8.08 & \\
\hline & $\mathrm{CaO}$ & 8.33 & \\
\hline & $\mathrm{SO}_{3}$ & 5.10 & \\
\hline & $\mathrm{K}_{2} \mathrm{O}$ & 2.05 & \\
\hline & $\mathrm{Na}_{2} \mathrm{O}$ & 1.79 & \\
\hline & $\mathrm{P}_{2} \mathrm{O}_{5}$ & 0.221 & \\
\hline
\end{tabular}

$50 \mathrm{ppm}$ synthetic As (V) solution was prepared from standard arsenic solution (Merck KGaA, Darmstadt, Germany) with double deionized water.

\section{Batch Adsorption Experiments}

The batch adsorption experiments were conducted to decide optimum adsorption parameters by changing experimental parameters. The amount adsorbent was set to $0.5 \mathrm{~g}$ after preliminary studies and temperature had controlled magnetic stirrer was used during studies. When initial As (V) concentration $(50 \mathrm{ppm})$, adsorbent weight $(0.5 \mathrm{~g}), \mathrm{pH}(2)$ and the stirring speed were kept constant, the contact time and adsorption temperature were varied between 5-180 min and 30-50 ${ }^{\circ} \mathrm{C}$, respectively.

After determined adsorption time, the residual As (V) concentration was determined by Inductively Coupled Plasma - Optical Emission Spectrometer (ICP-OES) (Optima DV 2100, Perkin Elmer, USA). The concentration of As $(\mathrm{V})$ remained in the adsorbent phase $\left(\mathrm{q}_{\mathrm{e}}, \mathrm{mg} / \mathrm{g}\right)$ was calculated by the equation (1) (Qui et al., 2015):

$$
\mathrm{q}_{\mathrm{e}}=\frac{C_{i}-C_{f}}{m} x V
$$

where $\mathrm{V}$ is the volume of solution $(\mathrm{mL}), \mathrm{m}$ is the weight of adsorbent $(\mathrm{g}), \mathrm{C}_{\mathrm{i}}$ and $\mathrm{C}_{\mathrm{f}}$ are the initial and final concentration of As (V) (mg/L), respectively (Qiu et al., 2015). The As (V) removal efficiency of bottom ash (R \%) was calculated by following equation (2) (Cheraghi et al., 2015):

$$
R(\%)=\frac{C_{i}-C_{f}}{C_{i}} x 100
$$


Adsorption Isotherms

Adsorption isotherms give information about the interaction between solute and adsorbent surface at a constant temperature. Langmuir and Freundlich's isotherms were used to analyze equilibrium data. According to Langmuir isotherm theory, adsorption takes place by monolayer coverage of adsorbate onto the homogenous adsorbent surface (Hameed, 2009). Langmuir isotherm is given as;

$$
q_{e}=\frac{q_{\max } K_{L} C_{e}}{1+K_{L} C_{e}} x V
$$

where qmax is maximum adsorption capacity of adsorbent $(\mathrm{mg} / \mathrm{g})$, Ce is the concentration of As $(\mathrm{V})$ in the solution at equilibrium $(\mathrm{mg} / \mathrm{L})$ and $\mathrm{KL}$ is Langmuir constant related to the affinity of the binding sites (Bhattacharya et al., 2008; Hameed, 2009). In Langmuir isotherms, the separation factor of RL is used to indicate the essential characteristics of the isotherm. When RL is between 0 and 1, it expresses that the adsorption is favorable (Hameed, 2009).

$$
R_{L}=\frac{1}{1+K_{L} C i}
$$

Freundlich's isotherm is expressed as equation (5),

$$
\operatorname{In} q_{e}=\operatorname{In} K_{F}+\frac{1}{n} \operatorname{In} C_{e}
$$

where $K_{F}$ is Freundlich constant related adsorption capacity of adsorbents, $n$ is constant about the intensity of adsorption. The values of $K_{F}$ and $\mathrm{n}$ can be determined from the plot of $I n q_{e}$ versus $I n C_{e}$ (Qui et al., 2015; Uddin et al., 2009).

\section{Adsorption Kinetics}

The experimental results were fitted to the two common kinetic models, namely Lagergren pseudofirst order kinetic model, pseudo-second order kinetic model, to investigate kinetic parameters and mechanism of As (V) adsorption onto the bottom ash. Lagergren pseudo-first order kinetic model is represented as following form (6),

$$
\frac{d q_{t}}{d t}=k_{1}\left(q_{e}-q_{t}\right)
$$

where $k_{l}$ is the pseudo-first order rate constant $\left(\mathrm{min}^{-1}\right), q_{t}$ and $q_{e}$ are amounts of adsorbed As (V) per unit mass of adsorbent at time $t$ and equilibrium time $(\mathrm{mg} / \mathrm{g})$, respectively. Pseudo-second order kinetic model can be expressed as given in the equation (7),

$$
\frac{d q_{t}}{d t}=k_{1}\left(q_{e}-q_{t}\right)^{2}
$$

and $k_{2}$ is the pseudo-second order rate constant (g/mg.min).

The appropriate kinetic model which explains kinetics and mechanisms of As (V) adsorption onto the bottom ash can be determined by drawing linear plots for each kinetic models and calculation correlation coefficient of $\mathrm{R}^{2}$. 


\section{Results and Discussions}

Adsorption results

The effects of contact time and adsorption temperature on the As (V) adsorption and removal percentage of As $(\mathrm{V})$ are shown in Figure 1 and Figure 2, respectively. It can be seen that the amount of adsorbed As (V) per unit mass of adsorbent increased by increasing contact time. In the initial stages, the removal of As (V) was rapid. However, after 60 minutes of contact time, the system reached the equilibrium, and the adsorbed amount did not show a significant difference. This phenomenon can be explained by the higher amounts of the available adsorbent surface for As (V) at the initial adsorption times.

The adsorption capacity of bottom ash showed similarity for each adsorption temperatures. On the other hand, the values of $\mathrm{q}_{\mathrm{e}}$ at $30^{\circ} \mathrm{C}$ were bigger than those at higher temperatures, from which it can be deduced that the adsorption behavior of As (V) is more efficient at low temperature.

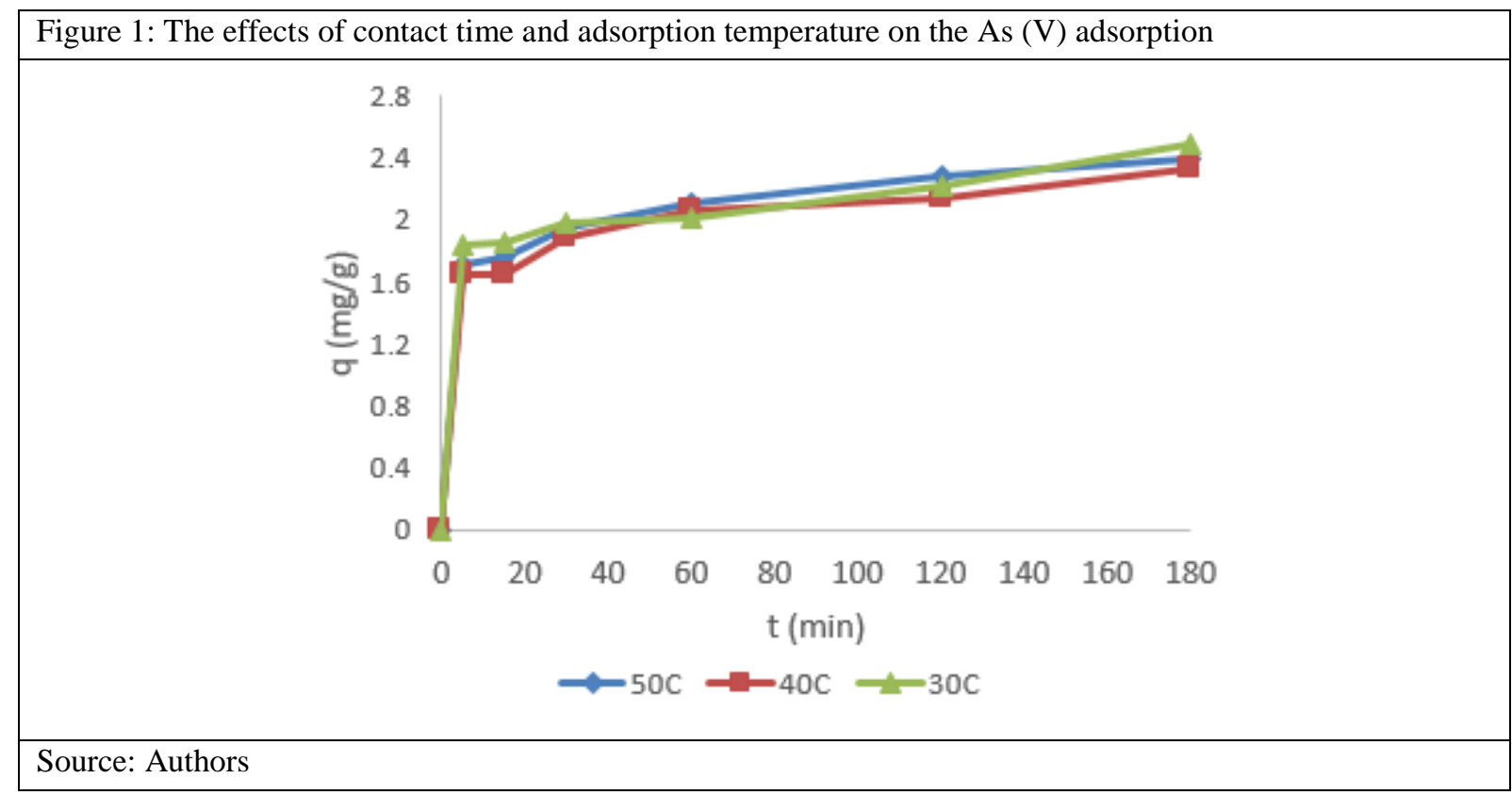

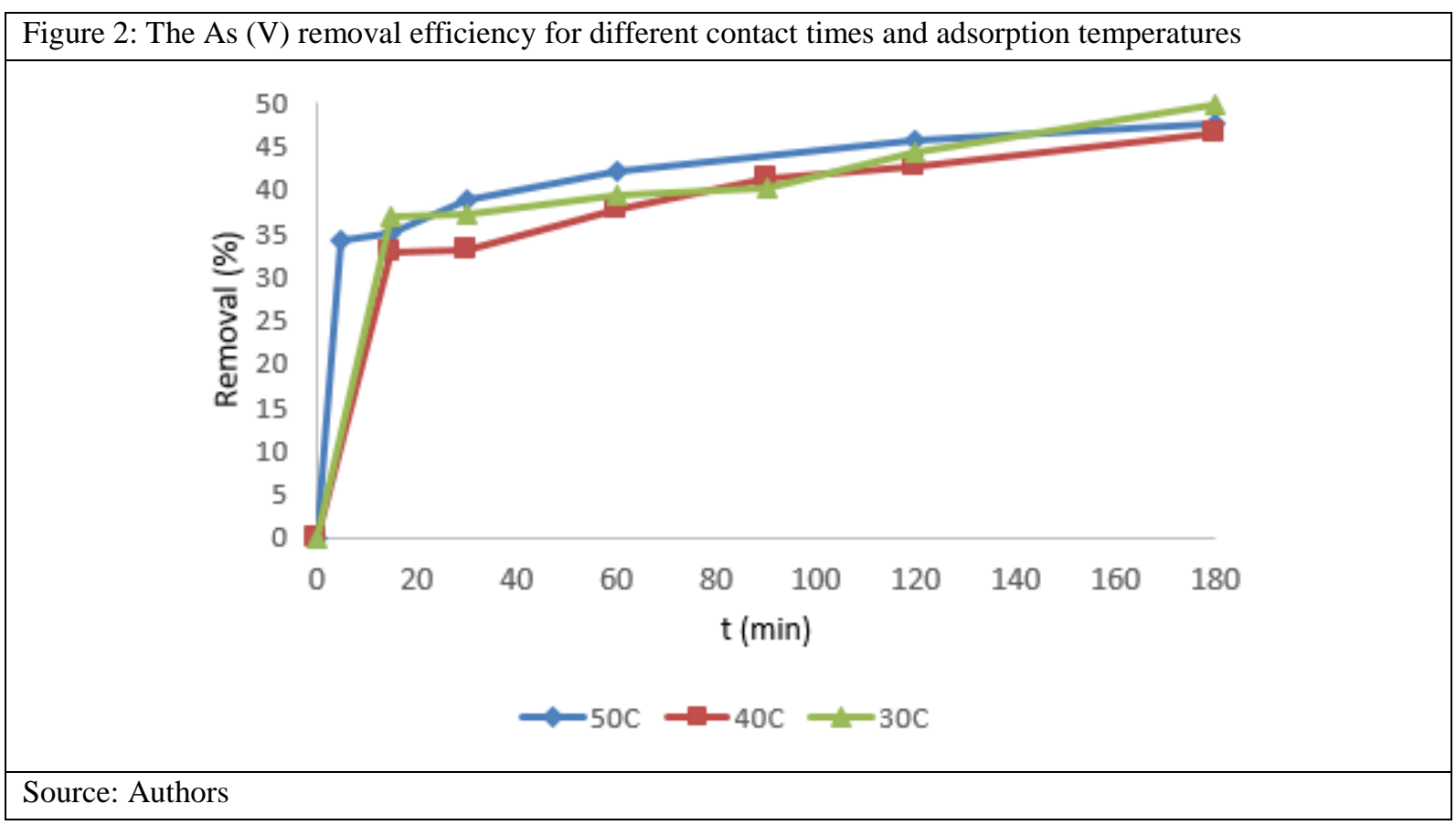




\section{Adsorption Isotherms}

The calculated isotherm parameters and correlation coefficients $\left(\mathrm{R}^{2}\right)$ are given in Table 2. The equilibrium data were better fitted by the Freundlich isotherm model than done by Langmuir isotherm equation. For all studied temperatures, high $\mathrm{R}^{2}$ values were indicating that the obtained data were in good agreement with the Freundlich model, which implies that the surface of adsorption is heterogeneous and there are many types of active adsorption sites on the adsorbent. The obtained $n$ values were smaller than one which means the adsorption carried out by a chemical process which is associated with a higher adsorption enthalpy and slower kinetics of adsorption than physical adsorption (Orakwue et al., 2016).

Table 2: Parameters of Freundlich isotherm model for As (V) adsorption

\begin{tabular}{|c|c|c|c|c|}
\hline Isotherm & Temperature $\left({ }^{\circ} \mathbf{C}\right)$ & \multicolumn{3}{|c|}{ Parameters } \\
\cline { 3 - 5 } & & $\mathbf{R}^{\mathbf{2}}$ & $\mathbf{n}$ & $\mathbf{K}_{\mathbf{F}}$ \\
\hline \multirow{3}{*}{ Freundlich } & 50 & 0.998 & 0.408 & 0.004 \\
\cline { 2 - 5 } & 40 & 0.998 & 0.390 & 0.002 \\
\cline { 2 - 5 } & 30 & 0.998 & 0.432 & 0.006 \\
\hline
\end{tabular}

Source: Authors

\section{Adsorption Kinetics}

Table 3 represents the summary of data calculated for pseudo first-order and pseudo-second order model. Also, Figure 3 and Figure 4 show the pseudo-first order and pseudo second order plots for different adsorption temperatures ranging from 30 to $50{ }^{\circ} \mathrm{C}$. According to the correlation coefficients $\left(\mathrm{R}^{2}=0.998\right)$, it could be concluded that the pseudo-second order kinetic model can be used to describe the adsorption process of As $(\mathrm{V})$. It shows that the chemisorption of $\mathrm{As}(\mathrm{V})$ ions was the ratedetermining step of the adsorption process. This process contains the chemical interaction between $\mathrm{As}(\mathrm{V})$ ions and polar groups on the adsorbent, such as ion exchange and chelating reaction (Zhou et al., 2016; Yang et al., 2016). For $50{ }^{\circ} \mathrm{C}, 40{ }^{\circ} \mathrm{C}, 30{ }^{\circ} \mathrm{C}$ the pseudo second order rate constant $\mathrm{k}_{2}$ were calculated as $0.034 \mathrm{~g} / \mathrm{mg} . \mathrm{min}, 0.033 \mathrm{~g} / \mathrm{mg} . \mathrm{min}$ and $0.030 \mathrm{~g} / \mathrm{mg} . \mathrm{min}$.

\begin{tabular}{|l|c|c|c|c|c|}
\hline \multicolumn{6}{|l|}{ Table 3: Kinetic parameters for As (V) adsorption } \\
\hline Kinetic model & $\begin{array}{c}\text { Temperature } \\
\left({ }^{\circ} \mathbf{C}\right)\end{array}$ & \multicolumn{5}{|c|}{ Parameters } \\
\cline { 2 - 6 } & & $\mathbf{R}^{\mathbf{2}}$ & $\mathbf{k}_{\mathbf{1}}\left(\mathbf{m}^{-1}{ }^{-1}\right)$ & $\mathbf{k}_{\mathbf{2}}$ (g/mg.min) & $\mathbf{q}_{\mathbf{e}}$ (mg/g) \\
\hline \multirow{3}{*}{$\begin{array}{l}\text { Pseudo-first } \\
\text { order }\end{array}$} & 50 & 0.922 & 0.018 & - & 1.052 \\
\cline { 2 - 7 } & 40 & 0.983 & 0.013 & - & 0.913 \\
\cline { 2 - 7 } & 30 & 0.857 & 0.008 & - & 0.788 \\
\hline \multirow{3}{*}{$\begin{array}{l}\text { Pseudo-second } \\
\text { order }\end{array}$} & 50 & 0.995 & - & 0.034 & 2.385 \\
\cline { 2 - 7 } & 40 & 0.995 & - & 0.033 & 2.322 \\
\hline
\end{tabular}

According to the pseudo-second order kinetic model, the predicted adsorption density $\mathrm{q}_{\mathrm{e}}$ at equilibrium values were close to the experimental $\mathrm{q}_{\mathrm{e}}$ values. The good agreement between the predicted and experimental values of $\mathrm{q}_{\mathrm{e}}$ shows that the pseudo-second order kinetic model represents the adsorption kinetics of As (V) onto the bottom ash. 


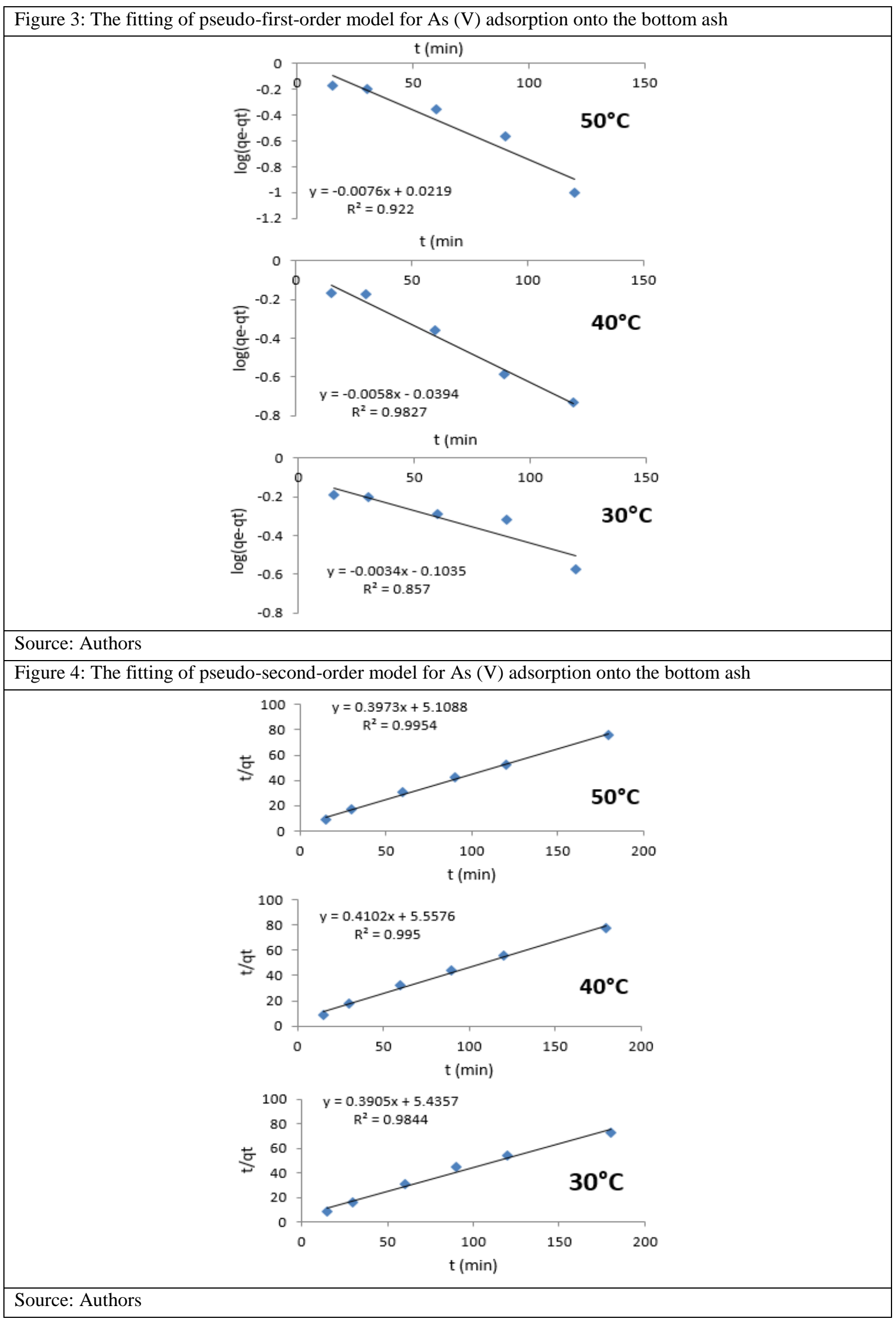




\section{Conclusion}

The present investigation showed that bottom ash could be an effective adsorbent for the removal As (V) ions from the aqueous solution. The experimental study with different parameters showed that adsorption temperature did not have a significant effect on the removal of As (V) onto the bottom ash when increasing contact time increased the adsorbed amount of As (V) up to 60 minutes.

The equilibrium data were fitted to the different isotherm models, and the equilibrium data were best described by Freundlich's isotherm. Kinetics for the removal of As (V) were obtained and fitted to various kinetics models. The pseudo-second order kinetic model provided a good correlation for the adsorption process, and the result showed that this process is suggesting that chemisorption controlled the adsorption process.

\section{References}

Banerji, T., \& Chaudharia, S. (2016). Arsenic removal from drinking water by electrocoagulation using iron electrodes- an understanding of the process parameters. Journal of Environmental Chemical Engineering, 4 (2016) 3990-4000.

Bhattacharya, A.K., Naiya, T.K., Mandal, S.N., \& Das, S.K. (2008). Adsorption, kinetics and equilibrium studies on removal of $\mathrm{Cr}(\mathrm{VI})$ from aqueous solutions using different low-cost adsorbents. Chemical Engineering Journal. 137(3) 529-541.

Cheraghi, M., Sobhanardakani, S., Zandipak, R., Lorestani, B., \& Merrikhpour, H. (2015). Removal of Pb (II) from aqueous solutions using waste tea leaves. Iranian Journal of Toxicology. 9 (28) 1247-1253.

Duruibe, J. O., Ogwuegbu, M. O. C., \& Egwurugwu, J. N. (2007). Heavy metal pollution and human biotoxic effects. International Journal of Physical Sciences, 2 (5) 112-118.

Eliche-Quesada, D., Felipe-Sesé, M. A., Moreno-Molina, A. J., Franco, F., \& Infantes-Molina, A. (2017). Investigation of using bottom or fly pine-olive pruning ash to produce environmental friendly ceramic materials. Applied Clay Science 135 (2017) 333-346.

Fonteboa, B. G., Carro-Lopez, D., Brito, J., Martınez-Abella, F., Seara-Paz, S., \& Gutierrez-Mainar, S. (2017). Comparison of ground bottom ash and limestone as additions in blended cements. Materials and Structures (2017) 50:84. DOI $10.1617 / \mathrm{s} 11527-016-0954-\mathrm{x}$

Hameed, B.H. (2009). Spent tea leaves: A new non-conventional and low-cost adsorbent for removal of basic dye from aqueous solutions. Journal of Hazardous Materials. 161 (2009) 753-759.

Lin, C.Y., \& Yang, D.H. (2002). Removal of pollutants from wastewater by coal bottom ash. Journal of environmental science and health. Part A, Toxic/hazardous substances \& environmental engineering. 37(8):1509-1522.

Noh, S. \& Son, Y. (2017). Substitution effects of forest aggregates for bottom ash based on the economic value for forestry and carbon dioxide emissions. Journal of Cleaner Production. 141 (2017) 1178-1185.

Orakwue, E. O., Asokbunyarat, V., Rene, E. R., Lens, P. N. L., \& Annachhatre A. (2016). Adsorption of Iron(II) from acid mine drainage contaminated groundwater using coal fly ash, coal bottom ash, and bentonite clay. Water Air Soil Pollution. (2016) 227: 74.

Qiu, G., Xie, Q., Liu, H., Chen, T., Xie, J., \& H. Li. (2015). Removal of Cu(II) from aqueous solutions using dolomitepalygorskite clay: Performance and mechanisms. Applied Clay Science. 118: 107-115.

Uddin, T., Islam, A., Mahmud, S., \& Rukanuzzaman. (2009). Adsorptive removal of methylene blue by tea waste. Journal of Hazardous Materials 164 (2009) 53-60

Yang, S., Wu, Y., Aierken, A., Zhang, M., Fang, P., Fan, Y., \& Ming, Z. (2016). Mono/competitive adsorption of Arsenic (III) and Nickel (II) using modified green tea waste. Journal of the Taiwan Institute of Chemical Engineers. 60 (2016) 213221.

Yang, X., \& Cui, X. (2013). Adsorption characteristics of Pb (II) on alkali treated tea residue. Water Resources and Industry. 3 (2013) 1-10.

Zhou, Z., Liu, Y., Liu, S., Liu, S., Zeng, G., Tan, X., Yang, C., Ding, Y., Yan, Z., \& Cai, X. (2017). Sorption performance and mechanisms of arsenic (V) removal by magnetic gelatin-modified biochar. Chemical Engineering Journal. 314 (2016) 223-231. 